\title{
AÇÕES EDUCATIVAS DE ENFERMAGEM EM SAÚDE BUCAL DE IDOSOS EM UMA INSTITUIÇÃO DE LONGA PERMANÊNCIA*
}

\author{
Denise Somavila Przylynski¹, Marlene Teda Pelzer², Silvana Sidney Costa dos Santos³ ${ }^{3}$ Marília Egues da Silva ${ }^{4}$, César \\ Francisco Silva da Costa ${ }^{5}$, Adriano Baraciol Gasparim ${ }^{6}$
}

\begin{abstract}
RESUMO: Foram objetivos deste estudo: conhecer a percepção da saúde bucal de idosos residentes em uma Instituição de Longa Permanência para Idosos-ILPI; identificar a presença de interferências nas relações interpessoais em idosos com condição bucal comprometida; orientar o idoso residente acerca de higienização bucal por meio de ações educativas. Pesquisa qualitativa, realizada em uma ILPI no Rio Grande-RS, Brasil, com 32 idosos residentes. Os dados foram coletados utilizando-se formulário estruturado, cuja análise foi realizada seguindo-se os passos da pesquisa convergente-assistencial. Os resultados corroboram a expectativa dos pesquisadores: os idosos sujeitos deste estudo possuem uma saúde bucal insatisfatória e sua socialização pode estar comprometida, uma vez que os dentes afetam a mastigação, fonação, deglutição e a estética, o que interfere diretamente na qualidade de vida. Ações educativas adequadas podem contribuir para melhoria na saúde bucal desses idosos.
\end{abstract}

PALAVRAS-CHAVE: Saúde bucal; Idoso; Educação em saúde; Enfermagem.

\section{EDUCATIVE NURSING ACTIONS IN MOUTH HEALTH IN A LONG PERMANENCE ELDERLY INSTITUTION}

\begin{abstract}
The objectives of this study were: knowing the elderly's mouth health perception among the ones living in a long permanence institution for elderly people (LPIEP); identifying interferences in interpersonal relations in elderly people with compromised mouth condition; orienting the elderly person about mouth hygiene using educative actions. Qualitative research, carried out in a LPIEP in Rio Grande/RS/Brazil , having 32 elderly people as subject. Data were collected using a structured questionnaire and were analyzed following the steps of assistance-convergent research. The results corroborate with the researchers expectation: elderly people of this study have an unsatisfactory mouth health condition and their socialization might be compromised, once their teeth affect mastication, speech, deglutition and esthetics, and interferes directly in life quality. Proper educative actions may contribute for better mouth health condition to these people.
\end{abstract}

KEYWORDS: Oral health; Aged; Health education; Nursing.

\section{ACCIONES EDUCATIVAS DE ENFERMERÍA EN SALUD BUCAL DE ANCIANOS EN UNA INSTITUCIÓN DE LARGA PERMANENCIA}

RESUMEN: Fueron objetivos de este estudio: conocer la percepción de la salud bucal de ancianos residentes en una Institución de Larga Permanencia para Ancianos; identificar la presencia de interferencias en las relaciones interpersonales en ancianos con condición bucal comprometida; orientar al anciano residente acerca de la higiene bucal, por medio de acciones educativas. Investigación cualitativa, realizada en una Institución de Larga Permanencia para Ancianos, en Río Grande/RS/Brasil, con 32 ancianos residentes. Los dados fueron colectados utilizándose cuestionario estructurado, cuyo análisis fue realizado siguiéndose los pasos de la investigación convergente-asistencial. Los resultados corroboran la expectativa de los investigadores: los ancianos sujetos de este estudio poseen una salud bucal insatisfactoria y su socialización puede estar comprometida, una vez que los dientes afectan la masticación, la fonación, deglución y la estética, lo que interfiere directamente en la calidad de vida. Acciones educativas adecuadas pueden contribuir para mejorar la salud bucal de estos ancianos.

PALABRAS CLAVE: Salud bucal; Anciano; Educación en salud; Enfermería.

\footnotetext{
*Este estudo foi parte de um projeto maior e interdisciplinar, intitulado "Saúde bucal de idosos residentes em uma Instituição de Longa Permanência: conhecimento e orientações específicas”. Financiado pelo CNPq e FAPERGS.

${ }^{1}$ Enfermeira do Hospital São Francisco de Paula-RS.

${ }^{2}$ Enfermeira. Doutora em Enfermagem. Gerontóloga. Professora da Graduação e da Pós-graduação da Escola de Enfermagem da Universidade Federal do Rio Grande-FURG. Líder do Grupo de Estudo e Pesquisa em Gerontogeriatria, Enfermagem/Saúde e Educação-GERON. ${ }^{3}$ Enfermeira. Doutora em Enfermagem. Gerontóloga. Professora da Graduação e da Pós-graduação em Enfermagem da FURG. Líder do GERON. Pesquisadora do CNPq.

${ }^{4}$ Estudante do Curso de Mestrado em Enfermagem da FURG. Integrante do GERON. Bolsita CAPES.

${ }^{5}$ Enfermeiro. Mestre em Enfermagem. Professor da Graduação em Enfermagem da FURG. Integrante do GERON.

${ }^{6}$ Estudante da Faculdade de Medicina da FURG-RS. Integrante do GERON.
}

Autor correspondente:

Denise Somavila Przylynksi

Hospital São Francisco de Paula

Rua Engenheiro Alfredo Huch, 475 - 96201-900 - Rio Grande-RS, Brasil

E-mail: d.prz@ibest.com 


\section{INTRODUÇÃO}

A institucionalização do idoso é uma temática delicada, uma vez que sua aceitação como alternativa de suporte social não é bem vista, embora esteja ocorrendo um significativo aumento na demanda pela Instituição de Longa Permanência para Idosos-ILPI ${ }^{(1)}$, locais antes denominados asilos, casas ou lares geriátricos. A visão negativa das ILPIs muitas vezes se dá pela desvalorização dos aspectos sociais e psicológicos na perspectiva da promoção da saúde.

A saúde bucal é parte integrante e essencial da saúde geral e também um fator determinante na qualidade de vida, autoestima e contato social ${ }^{(2)}$. Assim como todo o organismo, as estruturas orais sofrem ação do processo de envelhecimento e as alterações na cavidade bucal, podem comprometer algumas funções, como comunicação, alimentação e autoestima ${ }^{(3)}$.

Os tecidos que formam o sistema estomatognático: dentes, gengiva, ligamentos ósseos, palato duro e mole, garganta, língua e lábios são passíveis de sofrer alterações durante o envelhecimento. $\mathrm{O}$ epitélio bucal torna-se mais fino e menos queratinizado, ocorrendo um aumento na densidade celular, além de ocorrer também uma diminuição no potencial de regeneração das mucosas e na resistência às doenças ${ }^{(2)}$.

As glândulas salivares diminuem suas secreções com o envelhecimento, dificultando a deglutição( ${ }^{(4)}$. A xerostomia também favorece a formação de placas bacterianas, criando um meio favorável para o crescimento de bactérias cariogênicas ${ }^{(5)}$.

Nos dentes, com o passar dos anos, o atrito faz com que a superfície oclusal e os pontos de contato tornem-se mais aplainados. A língua também se modifica, aumentando no interior da boca do indivíduo desdentado, possivelmente pela transferência de funções fonéticas e mastigatórias à medida que se perdem os dentes ${ }^{(5)}$.

Existem algumas situações características na cavidade bucal do idoso devido ao processo de envelhecimento, como: hipofunção salivar, cáries radiculares, perdas dentais e doença periodontal ${ }^{(2)}$.

A hipofunção salivar ocorre devido a alguns fatores predisponentes como: uso de fármacos, diabetes não controlada e ansiedade. As cáries radiculares são lesões iniciadas nas superfícies das raízes dos dentes, principalmente quando se tem recessões gengivais, tendo como fatores predisponentes: precária higiene bucal, hipossalivação, uso de fármacos e presença de Doença Crônica NãoTransmissível-DCNT, que comprometam o autocuidado do idoso. As perdas dentais são decorrentes de uma saúde bucal precária, relacionada aos fatores sócio-demográficos como raça, baixa renda, uso de tabaco, gênero (feminino) e baixa escolaridade. Doença periodontal é uma infecção crônica dos tecidos de suporte dos dentes, com característica inflamatória ${ }^{(2)}$.

A higiene oral adequada ajuda a manter dentes, boca e lábios saudáveis, removendo restos alimentares, que são os principais causadores de problemas bucais, suavizando os odores e gostos desagradáveis, proporcionando uma sensação de conforto e bemestar $^{(6)}$.

As doenças incapacitantes, como demências, Parkinson e outras perdas funcionais com prejuízo manual e visual, afetam a saúde bucal. O idoso dependente tende a apresentar inadequadas condições bucais em relação ao independente, por não realizar seu autocuidado. É importante que o cuidador ou outro integrante da equipe de enfermagem, tenha conhecimento teórico de como proceder na higienização e conscientização ética para que não negligencie esse cuidado ${ }^{(7)}$.

A higienização bucal deve ser tratada com relevância, pois é capaz de proporcionar melhoras na qualidade de vida do idoso, uma vez que quando efetiva, diminui os principais problemas bucais e outros problemas de saúde sistêmica.

Os trabalhadores da enfermagem, acrescentando-se os cuidadores institucionais de idosos, necessitam atentar para as mudanças físicas, que envolvem a imagem do corpo, sem caracterizar o idoso como um ser em degeneração, só com perdas, mas, valorizando sua autoimagem, criando condições para que se sinta psicologicamente bem ${ }^{(8)}$.

A capacidade de aprender e adquirir novas habilidades diminui no idoso, porém isso não o impede de continuar aprendendo, uma vez que a motivação do aprendizado e o desempenho da atividade realizada são fatores que influenciam o aprendizado ${ }^{(9)}$.

A educação em saúde tem como objetivo promover a expansão das práticas de saúde junto à comunidade, como uma maneira de desenvolver na população uma postura crítica quanto à saúde e quanto à vida em geral ${ }^{(10)}$. Para isso, torna-se importante levar em consideração os conhecimentos já existentes por parte dos idosos, bem como suas necessidades e interesses. 
A presença do enfermeiro como organizador/ facilitador de ações educativas contribui para minimizar os problemas físicos e emocionais mais frequentes nas pessoas inseridas na fase da velhice.

Como principal relevância deste estudo para a enfermagem e a população em questão, destaca-se o empenho em investir na melhoria da saúde bucal de idosos institucionalizados, considerando a precária situação relacionada à higienização bucal que reflete diretamente na qualidade de vida dos idosos, principalmente dos que residem em ILPI.

Partindo das reflexões foram questionamentos desta pesquisa: quais as percepções da saúde bucal, pelos idosos em uma ILPI do município do Rio GrandeRS-Brasil? Existe interferência nas relações interpessoais em idosos com condição bucal comprometida? É possível a orientação do idoso residente acerca de higienização bucal, utilizando-se de ações educativas?

Foram objetivos desta investigação: Conhecer as percepções da saúde bucal de idosos em uma ILPI; Identificar a presença de interferência nas relações interpessoais em idosos com condição bucal comprometida; Orientar o idoso residente acerca de higiene bucal, utilizando-se de ações educativas.

\section{METODOLOGIA}

Pesquisa qualitativa, convergente-assistencial, a qual mantém uma estreita relação com a situação social do pesquisado, e articula a prática profissional com o conhecimento teórico. Compreende o pesquisado como sujeito partícipe e co-responsável na investigação, por meio de elementos essenciais no fazer da indagação, da subjetividade e do sentimento ${ }^{(11)}$.

Realizado em uma ILPI mista, filantrópica e de fins lucrativos, que tem como fonte de receita a aposentadoria dos residentes e doações da comunidade da cidade do Rio Grande, Rio Grande do Sul-Brasil. Nesta ILPI residem 70 idosos, dos quais 32 atenderam aos critérios de inclusão na pesquisa: concordância em participar da pesquisa, por meio da assinatura e/ ou colocação de impressão digital no Termo de Consentimento Livre e Esclarecido-TCLE e possuir estado cognitivo preservado. A cognição dos participantes foi previamente identificada através de consulta ao prontuário do residente, em que consta o escore do Mini-exame do Estado Mental-MEEM. Cada idoso foi identificado como Idoso Residente, seguido de um número de ordem, como R1, R2, R3, respectivamente, para preservação da identidade.

A coleta de dados foi realizada no segundo semestre de 2008 e utilizou-se da gravação de entrevistas estruturadas. Dois pesquisadores aplicaram o formulário contendo dados de identificação e dados relacionados à percepção dos idosos sobre saúde bucal.

A análise dos dados se deu por: processo de apreensão, que é a organização dos relatos das informações, mantendo-se os registros numa ordem cronológica, data e número da entrevista; processo de síntese, nela o pesquisador examina subjetivamente as associações e variações das informações, novamente imerge nas informações e tem domínio sobre elas; processo de teorização consiste em descobrir os valores contidos nas informações, a interpretação é realizada à luz da fundamentação teórica, associando-a aos dados analisados; processo de transferência, consiste na possibilidade de encontrar significados aos achados, procurando contextualizá-los ${ }^{(11)}$. A partir daí, surgiram como temas significativos pelos idosos sobre saúde bucal: perdas dos dentes, importância da saúde bucal, higienização bucal.

A aplicação do instrumento de coleta de dados foi efetivada após o consentimento do diretor da ILPI investigada e aprovação da pesquisa pelo Comitê de Ética e Pesquisa da Área da Saúde-CEPAS-FURG, com parecer favorável número 79/2007.

\section{APRESENTAÇÃO E DISCUSSÃO DOS DADOS}

Os resultados são apresentados considerando a caracterização dos sujeitos, os temas significativos sobre saúde bucal e o desenvolvimento da educação em saúde, voltada aos idosos residentes em uma ILPI.

\section{Caracterização dos idosos}

Dos 32 participantes na pesquisa, 21 foram do sexo feminino, em sua maioria viúvas, e 11 do sexo masculino, sendo estes, na maioria, solteiros. A menor taxa de mortalidade da população feminina faz com que as taxas dessa população sejam superiores à masculina $^{(12)}$.

A idade dos residentes variou de 63 anos a 107 anos, tendo uma maior prevalência entre 70 e 79 anos. Quanto ao nível educacional, 16 sujeitos da pesquisa não sabem ler e escrever, outros, cursaram de 2 a 3 anos de escola. Considere-se que o baixo nível de escolaridade pode ser uma barreira no processo de educação em saúde, exigindo, que os trabalhadores 
de saúde utilizem os mais diferentes recursos e dinâmicas, para alcançar as metas desejadas ${ }^{(13)}$.

\section{Temas significativos pelos idosos sobre saúde bucal}

\section{Perda dos dentes}

Os idosos já tinham perdido algum dente, e grande parte é totalmente edêntulo. A maioria deles faz uso de prótese. Os depoimentos confirmam o conceito errôneo que a sociedade tem de que as perdas dentárias fazem parte do processo de envelhecimento:

Não achei ruim perder os dentes, porque todos perdem [...] (R11).

Não significou nada perder os dentes e não fiquei triste, porque coloquei a dentadura (R29).

Alguns idosos reagem às perdas dentárias de forma conformista e depressiva, enfrentando a perda dos dentes como algo próprio à idade, mostrando-se passivos diante da situação. O uso da prótese visa à superação de uma falha corporal, sendo um recurso de retorno à imagem que se quer continuar tendo e que é exigida pela sociedade ${ }^{(14)}$. A conformidade da situação se evidencia, quando se perguntou aos idosos como avaliavam sua saúde bucal e 23 deles julgaramna adequada. No entanto, alguns idosos reagem de forma contrária em relação às perdas dentárias:

Sinto tristeza, não é como ter os dentes próprios (R4).

Senti-me mal, foi ruim me acostumar (R14).

A percepção da condição bucal e sua importância é que condicionam o comportamento do indivíduo. Na maioria das vezes a razão para as pessoas não procurarem o atendimento odontológico previamente é a não percepção de suas necessidades ${ }^{(15)}$. Dessa forma, as perdas dentais representam o resultado final de um processo de saúde bucal pobre e interpretado como natural. Torna-se necessário extinguir esse estigma de que todo idoso é ou será desdentado, e a forma de conseguir isto é investir em ações educativas.

\section{Importância da saúde bucal}

A grande parte dos idosos entrevistados relaciona a importância da saúde bucal com a capacidade de se alimentar:

Sim, é muito importante para comer bem (R3).

Sim, muito importante, pois é mais fácil para comer (R6).

Os idosos edêntulos ou com número reduzido de dentes podem apresentar a função mastigatória comprometida, o que pode levá-los a escolher os alimentos que lhe dão maior conforto mastigatório, que são na maioria das vezes, ricos em carboidratos e gorduras $^{(2)}$, contribuindo fortemente para as alterações na saúde bucal, como cárie periodontal e posteriormente a perda do dente. Devido à procura por alimentos mais macios, o idoso priva-se de alimentos como carne, frutas, entre outras, causando um déficit nutricional em seu organismo.

Alguns idosos relacionaram a importância da saúde bucal com a fala, a comunicação:

É muitíssimo importante se preocupar com a saúde da boca, para a alimentação, para falar, para sorrir $[\ldots](R 8)$.

Claro que sim! É muito importante se preocupar com a saúde bucal, porque sem os dentes a gente parece nua, a pessoa não fala direito, não come direito e é importante também para a estética (R19).

As ações de se comunicar e se alimentar integram o ser humano com o meio no qual se encontra, e por isso a fala é vista como uma ferramenta que mantém o indivíduo agregado à sociedade, quando impedido de realizar as atividades sociais devido aos problemas na comunicação, este apresenta tendência ao isolamento ${ }^{(3)}$.

Como se verificou nos depoimentos, o sorriso, a estética, são muitos lembrados quando se diz respeito à saúde bucal. O sorriso anuncia bem-estar, alegria, segurança, auto-satisfação, satisfação em relação ao outro. A inibição do sorriso acontece quando o indivíduo não está contente com a aparência da boca, o que traz consequências para essa pessoa, pois destrói a postura desejável, diminuindo a autoestima, além de impedir a demonstração de alegria, prejudicando o convívio social ${ }^{(14)}$.

Uma tendência do ser humano frente a alguma alteração é a dificuldade de convívio com outras 
pessoas, o que inicialmente leva ao isolamento social, e se não for tratado, pode levar à depressão. Tais dificuldades podem ou não está presente nos idosos, conforme depoimentos:

Não tenho dificuldade de convívio com outras pessoas, só quando a prótese cai, aí me sinto envergonhada (R7).

Às vezes fico meio acanhada em sorrir, falar (R28).

Sim, tenho dificuldade de convívio com outras pessoas, porque lavo, lavo a boca e ela fede, percebo que as pessoas se afastam, não converso de pertinho (R30).

A dificuldade de convívio foi relatada por alguns idosos e se dá principalmente pela baixa autoestima. O idoso que não está contente com sua aparência física sente-se envergonhado perante os outros. É preciso motivar esse idoso para o autocuidado e fazê-lo perceber a importância que este tem no meio em que convive.

A boa aparência é elemento facilitador para as trocas sociais, pois o indivíduo aprendeu a avaliar-se segundo a apreciação dos outros; aprendeu que sua imagem conta mais que a experiência, a habilidade, os afetos e o caráter, uma vez que será julgado, inicialmente pela visibilidade exterior ${ }^{(14)}$.

\section{Higienização bucal}

Deve-se higienizar os dentes com escova macia, pelo menos 3 vezes ao dia, segurando a escova de modo que ela faça um ângulo de $45^{\circ} \mathrm{com}$ as gengivas e os dentes. As gengivas também devem ser escovados ${ }^{(9)}$. De acordo com os depoimentos os idosos descreveram a presença ou ausência da higienização bucal:

Escovo todos os dias com pasta. De 2 a 3 vezes por dia (R11).

Nada, não faço nada para limpar a boca (R18).

Enxáguo a boca com água e escovo a prótese com creme dental (R22).

Só lavo com água, se escovo dói (R30).

Pelos depoimentos se pode perceber as diversas maneiras de higienização bucal utilizadas pelos idosos. Tais dados confirmam o desconhecimento de medidas eficazes para combater as alterações na saúde bucal. É urgente a conscientização dos trabalhadores em atentar para a saúde bucal do idoso, pois muitos destes possuem alteração na cavidade oral pelo simples fato de nunca terem sido orientados a manter uma higienização correta.

\section{Ações educativas}

As ações educativas foram realizadas individualmente, de forma a manter a privacidade do idoso. Foi utilizado material didático: uma boca de cerâmica e uma escova para dentes, em tamanho grande; escovas para dentes e creme dental, que foram fornecidos para os idosos que não possuíam, ou que a possuíam, mas sem condições de uso. Tomou-se cuidado para realizar a ação educativa em um momento em que o idoso estivesse descansado e disposto a participar, longe dos horários das refeições e do banho, para assim não comprometer a ação educativa.

A ação educativa é uma das alternativas mais importantes para garantir a autonomia e independência do idoso, no entanto, o modelo assistencial privilegia as ações curativas, desconsiderando o importante papel que o cuidado voltado à promoção da saúde pode desempenhar ${ }^{(13)}$.

O despreparo dos trabalhadores que cuidam dos idosos institucionalizados é claro. Só a dedicação e o conhecimento das necessidades básicas não bastam. $\mathrm{O}$ trabalhador necessita buscar fontes diferenciadas de conhecimento. Um enfoque necessário ao cuidado é o respeito pelos significados do idoso diante do autocuidado. No cuidado que se realiza com ele e para ele, o trabalhador deve ter como princípio de que é o orientador essencial para a promoção do cuidado do idoso $^{(16)}$.

O enfermeiro necessita desenvolver estratégias de educação em saúde, levando em consideração a história de vida da população e estimulando a autoconfiança. A educação em saúde objetiva capacitar os indivíduos em busca de melhorias das condições de saúde e necessita estimular o diálogo, a indagação e a reflexão ${ }^{(13)}$.

Ao abordar o idoso, partia-se do conhecimento que ele já possuía a respeito da saúde bucal e como ele procedia na sua própria higienização. Pois, torna-se necessário levar em consideração os interesses do idoso e seus conhecimentos prévios, a fim de que este passe

Cogitare Enferm 2009 Out/Dez; 14(4):696-702 
de espectador e se torne sujeito das atividades ${ }^{(10)}$.

À medida que os idosos demonstravam como procediam na higienização bucal, procurava-se os pontos positivos, a fim de despertar a capacidade de confiança em si mesmo e aos poucos ia-se acrescentando novos conhecimentos. Grande parte dos entrevistados nunca havia recebido orientações acerca da higienização da língua. Assim, os idosos foram estimulados a escová-la, de modo a não permitir o surgimento da saburra lingual, que pode comprometer o paladar.

Como grande parte dos idosos faz uso de prótese, as orientações foram centralizadas no cuidado com as mesmas, que é similar ao desenvolvido com os dentes. O idoso deve retirar a prótese para a escovação e, antes de reintroduzi-la na cavidade oral, as gengivas e a língua devem ser limpas com uma escova macia. Massagear as gengivas com uma escova ou o polegar ajuda a estimular a circulação e a enrijecer a mucosa oral ${ }^{(17)}$.

Muitos dos idosos, não retiram as próteses para dormir, como se verificou nos depoimentos seguintes:

\section{É muito ruim, já acostumei dormir com as} dentaduras (R9).

Já fui orientada a dormir sem as próteses, mas não gostei, vou tentar de novo (R12).

As dentaduras devem ser removidas à noite, a fim de expor os tecidos ao ar. Durante as ações educativas os idosos foram estimulados a expor suas dúvidas sobre a manutenção da saúde bucal, bem como orientados sobre o conforto e bem-estar que a higienização bucal promove, contribuindo para melhoria de sua qualidade de vida.

\section{CONSIDERAÇÕES FINAIS}

Verificou-se que os idosos estudados possuíam uma saúde bucal insatisfatória, tendo afetada a sua socialização. Os dentes comprometidos ou a ausência deles, afetam a mastigação, fonação, deglutição e a estética, interferindo diretamente na qualidade de vida.

Faz-se necessário adotar, o quanto antes, medidas de promoção à saúde e ações educativas para esses idosos. Também se ressalta a necessidade de transformar o paradigma ainda vigente de que o idoso não merece investimentos, nem mesmo os voltados ao cuidado bucal, já que está no fim da vida.

Confirma-se que é dever do Estado, da família e da sociedade, garantir ao idoso um envelhecimento saudável e em condições de dignidade. No entanto, nota-se um esquecimento em relação à saúde bucal, principalmente pelo Estado. Mediante tal comprovação, os idosos estão sendo prejudicados, pois se alimentam mal, falam mal e sorriem pouco.

Ressalta-se a importância dos enfermeiros em se preocuparem com o cuidado da saúde bucal do idoso, uma vez que esta postura pode contribuir para melhoria da qualidade de vida dessas pessoas. É da enfermagem a responsabilidade de promover o conforto do idoso, o que inclui os cuidados com a higiene oral. Além dos cuidados com a higiene oral, quando necessário, o enfermeiro deve orientar e ensinar sobre a correta higienização.

O estudo permitiu conhecer a realidade acerca da saúde bucal de idosos residentes em ILPI, bem como se prestou cuidado necessário, utilizando ações de educação em saúde. Algumas dificuldades surgiram durante as entrevistas, por exemplo, as significativas internações hospitalares de alguns sujeitos do estudo, o que impediu de prestar cuidado educativo sistemático, pois alguns responderam ao formulário, porém, não participaram das ações educativas por conta desta hospitalização. Outra dificuldade foi localizar bibliografias para a pesquisa, considere-se que a ação de higienização bucal é um cuidado de enfermagem e necessita ser melhor aprofundado.

As ações educativas foram de extrema importância para os idosos. O idoso institucionalizado apresenta-se, muitas vezes, desmotivado, e a interação com novas informações se torna uma maneira de incentivá-los ao cuidado de higienização bucal.

Espera-se que esta investigação possa despertar o interesse dos enfermeiros em relação à saúde bucal do idoso. Essa ação só será de qualidade quando houver conscientização por parte dos trabalhadores que atuam em ILPI, os quais têm o compromisso de orientar à correta e devida manutenção da saúde bucal, podendo contribuir, assim, para manutenção da saúde geral e melhoria da qualidade de vida dos idosos institucionalizados.

\section{REFERÊNCIAS}

1. Siqueira MEC, Moi RC. Estimulando a memória em Instituições de longa permanência para idosos: manual de funcionamento. São Paulo: SBGG; 2003.

2. Padilha D, Hilgert JB, Hugo F. Saúde bucal. In: Freitas EVD, Py L, Cançado FAX, Gorzoni ML, organizadores. Tratado de geriatria e gerontologia. Rio de Janeiro: 
Guanabara Koogan; 2006. p. 1189-96.

3. Venites JP, Costa LS, Pelegrini P. Gerontologia, comunicação e alimentação. In: Ramos LR. Guias de medicina ambulatorial e hospitalar. São Paulo: Manole; 2005. p.243-54.

4. Roach R. Introdução à enfermagem gerontológica. Rio de Janeiro: Guanabara Koogan; 2003.

5. Luz DT. Saúde oral - odontogeriatria. In: Ramos LR. Guias de medicina ambulatorial e hospitalar. São Paulo: Manole; 2005. p. 325-39.

6. Potter PA, Perry AG. Grande tratado de enfermagem prática: clínica e prática hospitalar. São Paulo: Santos; 1998.

7. Shinkai RS, Cury AADB. O papel da odontologia na equipe interdisciplinar: contribuindo para a atenção integral ao idoso. Cad Saúde Publ. 2000 Out/ Dez;16(4):1099-1109.

8. Figueiredo NMA, Tonni T. Gerontologia: atuação do enfermeiro no processo de envelhecimento. São Caetano do Sul: Yendis; 2005.

9. Smeltzer SC, Bare BG. Tratado de enfermagem médicocirúrgica. Rio de Janeiro: Guanabara Koogan; 2002.

10. Souza EM, Lago SB. Educação para a saúde na terceira idade: relato de experiência. Estud Interdiscip Envelhec. 2002; 4(1): 125-33.

11. Trentini M, Paim L. Pesquisa em enfermagem: um desenho que une o fazer e o pensar na prática assistencial em enfermagem. $2^{\mathrm{a}}$ ed. Florianópolis: Insular; 2004.

12. Camarano AA. Os novos idosos brasileiros: muito além dos 60. Rio de Janeiro: IPEA; 2004.

13. Martins JJ, Albuquerque GL, Nascimento ERP, Barra DCC, Souza WGA, Pacheco WNS. Necessidades de educação em saúde dos cuidadores de pessoas idosas no domicílio. Texto Contexto Enferm. 2007 Abr/Jun; 16(2): 254-62.

14. Wolf SMR. O significado psicológico da perda dos dentes em sujeitos adultos. Rev APCD $1998 \mathrm{Jul} /$ Ago;52(4):307-16.

15. Silva SRC, Fernandes RAC. Autopercepção das condições de saúde bucal por idosos. Rev Saúde Publ. 2001; 35(4): 01-10.
16. Lenardt MH, Willig MSS, Shimbo AA, Maruo G. O idoso institucionalizado e a cultura de cuidados profissionais. Cogitare Enferm. 2006 Mai/Ago;11(2):117-23.

17. Craven RF, Hirnle CJ. Fundamentos de enfermagem: saúde e função humanas. Rio de Janeiro: Guanabara Koogan; 2006.

Cogitare Enferm 2009 Out/Dez; 14(4):696-702 